\title{
PERFORMANCE \& EMISSION OPTIMIZATION OF SINGLE CYLINDER DIESEL ENGINE TO MEET BS-IV NORMS
}

\author{
Mayur S. Sawade ${ }^{1}$, Sandeep S. Kore ${ }^{2}$ \\ ${ }^{1}$ Student, Mechanical Engineering, Sinhgad Academy of Engineering, Maharashtra, India \\ ${ }^{2}$ Associate Professor, Mechanical Engineering, Sinhgad Academy of Engineering, Maharashtra, India
}

\begin{abstract}
The growing cities, sharp increasing traffic, trajectory growth, rapid economic development and industrialization, and higher levels of energy consumption has resulted an increase of pollution load in the environment. It is also accepted that automobiles have emerged as a critical source of air pollution in the developing world. Realizing the gravity of the problem, steps are being taken to introduce better technologies, better fuel quality, shift to environment friendly fuels, and mass transit system for the control of environmental pollution in urban areas. Electronic diesel control, use of electronic FIE with increase in injection pressures and flexibility in injection control has changed the image of diesel engine. Engine optimization will lead to the better power with the better fuel economy which accomplish the urban living standard and care of the environment. Conventional fuel injection system was unable to fulfilment of this requirement, so it is necessity to modify fuel injection system along with vehicle after exhaust after treatment devices. Performance and Emission was optimized by using ETAS-INCA software. For the subject Bs-III engine, capacity is increased 50cc and certain modifications done. After proper optimization, with EGR ON the power value increased by $8.776 \%$ and torque value increased by $16.667 \%$ with respect to previous BS-III engine. Since the introduction of the new auxiliary system shows the gradual effect on the engine. According to the BS-IV norms the taper exhaust re-circulated by Oil Mist Separator (OMS) and to increase the performance the implementation of EGR Cooler is done. Also the BS-IV norms are achieved successfully in chassis dynamometer.
\end{abstract}

Keywords: BS-IV (Bharat Stage IV), INCA (Integrated Calibration and Data Acquisition), NO $($ Oxides of Nitrogen) $* * *$

\section{INTRODUCTION}

Particularly because of its economy and durability, the diesel engine has established itself as the choice for commercial vehicles. New electronically controlled diesel engine system with electronic controlled injection strategy gave new wings to diesel engine by separating high pressure generation is separated from the fuel metering. Managing injection is power full tool to control engine performance and emission levels. This rail less injection technology allows flexible fuel injection events in DI diesel engines by permitting free mapping of the start of injection, injection pressure, rate of injection with multiple injections like pilot and post injection events. Hence this new concept is drafted to achieve BS IV norms and to capture the market of single cylinder diesel engine in the future. For achieving this emission norms simultaneously without compromising fuel consumption and power the manufacturer needs to finely optimize the engine performance parameter.

This can be done with the help of the INCA (Integrated Calibration and Data Acquisition) software, With INCA software the data acquisition can be monitored in a computer monitor in an experiment window and the current engine operation can be monitored, stored and saved and optimized parameters can be flashed to ECU (Electronic Control Unit) and this newly flashed dataset values can be used further in the engine management system to get better performance result. . By means of INCA through which engine current operating condition can be monitored and altered by changing the pilot injection quantity, pilot separation, main injection quantity, main injection angle, main and pilot injection duration, EGR rate and many more parameters.

The bharat stage emission norms IV which will be followed are-

Table -1: Bharat stage norms-IV for light-duty diesel vehicles $(\mathrm{GVW} \leq 3,500 \mathrm{~kg})$

\begin{tabular}{|l|l|l|l|l|}
\hline Year & $\begin{array}{l}\mathrm{CO} \\
(\mathrm{gm} / \mathrm{km})\end{array}$ & $\begin{array}{l}\mathrm{HC}+\mathrm{NO}_{\mathrm{X}} \\
(\mathrm{gm} / \mathrm{km})\end{array}$ & $\begin{array}{l}\mathrm{NO}_{\mathrm{X}} \\
(\mathrm{gm} / \mathrm{km})\end{array}$ & $\begin{array}{l}\mathrm{PM} \\
(\mathrm{gm} / \mathrm{km})\end{array}$ \\
\hline 2010 & 0.50 & 0.30 & 0.25 & 0.025 \\
\hline
\end{tabular}

\subsection{Effect of Increasing Nozzle Opening Pressure}

It is believed that raising nozzle opening pressure improves atomization and widens the lean flame-out region the unburned hydrocarbon and carbon monoxide emissions reduced [2]. Comparatively with previous system injection pressure has been increased to achieve performance.

\subsection{Introduction of EGR Cooler}

The EGR is a prime technology for reducing NOx emissions. Adapting the cooler in the EGR path further reduced the NOx emissions by lowering the combustion temperature [3]. 


\section{OBJECTIVE OF OPTIMIZATION}

In the case of new electronically controlled diesel engine system which comes under SCV (Small Commercial Vehicle) category application the following attributes are optimized

\subsection{Torque and Power}

The main aim is to obtain the maximum possible torque under all operating conditions in order to be able to move heavy loads in even the most difficult situations.

\subsection{Pollutant Emission}

From April 2016 onwards, new commercial vehicles registered in India should satisfy BS4 emission norms. Hence engine adaptation must ensure that the limits for $\mathrm{NO}_{\mathrm{X}}, \mathrm{PM}, \mathrm{HC}$ and $\mathrm{CO}$ emission and exhaust opacity are reliably complied with.

\section{SPECIFICATION OF EXPERIMENTAL}

\section{ENGINE}

The specifications of the test engine used for present work is given in table- 2 as follows

Table -2: Specification of Engine

\begin{tabular}{|l|l|}
\hline Working Fluid & BS4 Diesel \\
\hline Number Of Cylinders & 1 \\
\hline $\begin{array}{l}\text { No. of Strokes Per } \\
\text { Cycle }\end{array}$ & 4 \\
\hline Engine Name & $\begin{array}{l}\text { Single cylinder Diesel } \\
\text { Engine }\end{array}$ \\
\hline Dry Weight & 57 Kg \\
\hline Intake System & Naturally Aspirated \\
\hline Cooling System & Water Cooled \\
\hline Metering System & Direct Injection, IMRL \\
\hline Peak BMEP & $\sim 7.8$ bar \\
\hline Compression Ratio & $18.5: 1$ \\
\hline Auxiliary System & $\begin{array}{l}\text { Cooled EGR Oil Mist } \\
\text { Separator (OMS) }\end{array}$ \\
\hline EGR & Proportional \\
\hline Emission Target & BS IV \\
\hline
\end{tabular}

\section{LAYOUT OF ENGINE TEST BED}

Following diagram shows closed loop position control EGR control. Since present engine is electronic controlled, naturally aspired coupled with eddy current dyanamometer. ECU is taking all the feedback from diffrent sensors, according to that it decides the fuel quantity and EGR opening valve position.

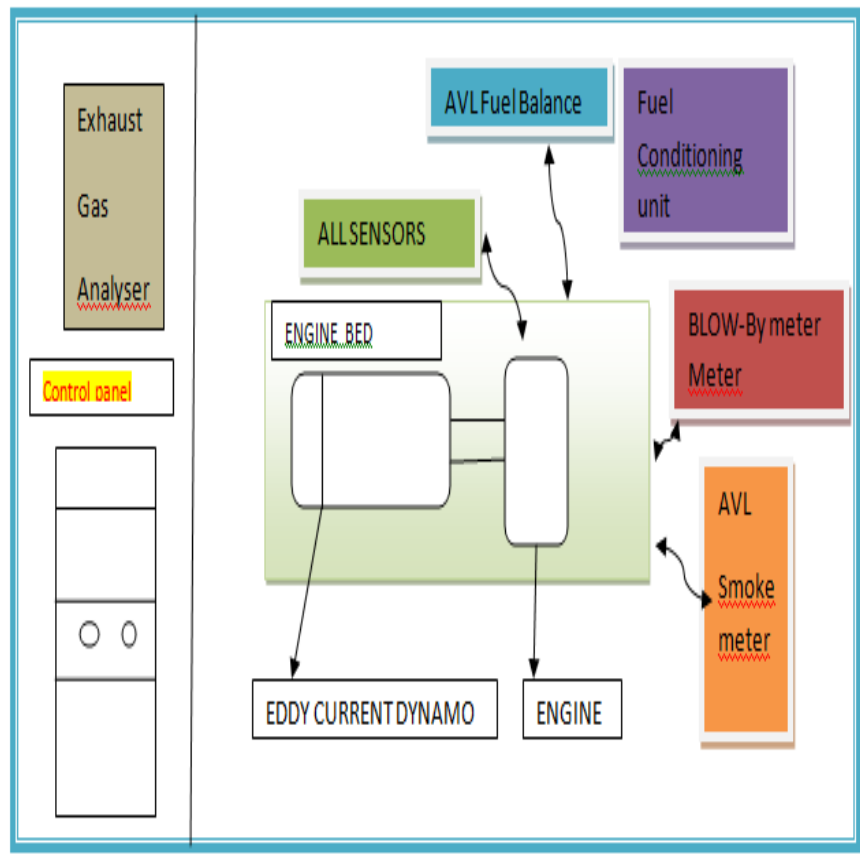

Fig -1: Engine test bed layout [3]

\section{MODIFICATIONS ON THE ENGINE}

To get the expected performance and emissions, certain modifications made on previous BS-III engine, these are follows

Table -3: Hardware adaption summary

\begin{tabular}{|l|l|l|}
\hline $\begin{array}{l}\text { Up-gradation } \\
\text { parameter }\end{array}$ & $\begin{array}{l}\text { BS-III } \\
\text { Engine }\end{array}$ & $\begin{array}{l}\text { BS-IV } \\
\text { Engine }\end{array}$ \\
\hline IMRL System & NA & Introduced \\
\hline $\begin{array}{l}\text { Piston Bowl } \\
\text { Shape }\end{array}$ & $\begin{array}{l}\text { Diameter= 12.76\% increased } \\
\text { Height=11.11\% decreased }\end{array}$ \\
\hline Technology & Mechanical & Electronic FIE \\
\hline Auxiliary systems & EGR & $\begin{array}{l}\text { EGR Cooler, Oil Mist } \\
\text { Separator(OMS) }\end{array}$ \\
\hline $\begin{array}{l}\text { Injection timing } \\
\text { Swing }\end{array}$ & $\begin{array}{l}\text { SIT= 12.5 } \\
\text { bTDC }\end{array}$ & $\begin{array}{l}\text { DIT, Pilot= 36.5 bMI } \\
\text { DIT, main=11.5 bTDC }\end{array}$ \\
\hline Rail Pressure & 600 bar & 1100 bar \\
\hline $\begin{array}{l}\text { Injector Hole ID } \\
\text { E*0.190*146 }\end{array}$ & $5 * 0.169 * 146$ \\
\hline EGR Rate & Uncontrolled & Controlled \\
\hline $\begin{array}{l}\text { After Exhaust } \\
\text { treatment }\end{array}$ & DOC & DOC+POC \\
\hline
\end{tabular}

After these modifications engine will be run on 13 mode speeds which vary from low idle to high idle (1200 rpm to $3500 \mathrm{rpm}$ ) and test will be carried out through the INCA software. The engine is connected with the eddy current dynamometer which decides the load on the engine given by operator. The engine ECU is connected to the server computer by CAN network cable. This cable gives real time values of engine fluctuations. The different sensors are connected to the ECU, which gives the accurate values like RPM, temperature, pressure, load on engine, etc. 


\section{RESULTS AND DISCUSSION}

The various results are carried out on the basis of different modifications made by $\mathrm{R} \& \mathrm{D}$ team. The final performance is carried out with the EGR flow ON, and graphs plotted of torque, power, BMEP and various emissions. Since the results are shown in the percentage increment as the vehicle and engine has not launched yet, thus according with confidentiality and the agreement with the company, the final results are shown only in percentage.

\subsection{EGR Mapping}

In previous system the flow of the EGR is constant through the $4 \mathrm{~mm}$ pipe, but in the present system the EGR is connected through the ECU which sense the input signals given by the sensors and decides the value of EGR quantity. The observed quantity of EGR is given by

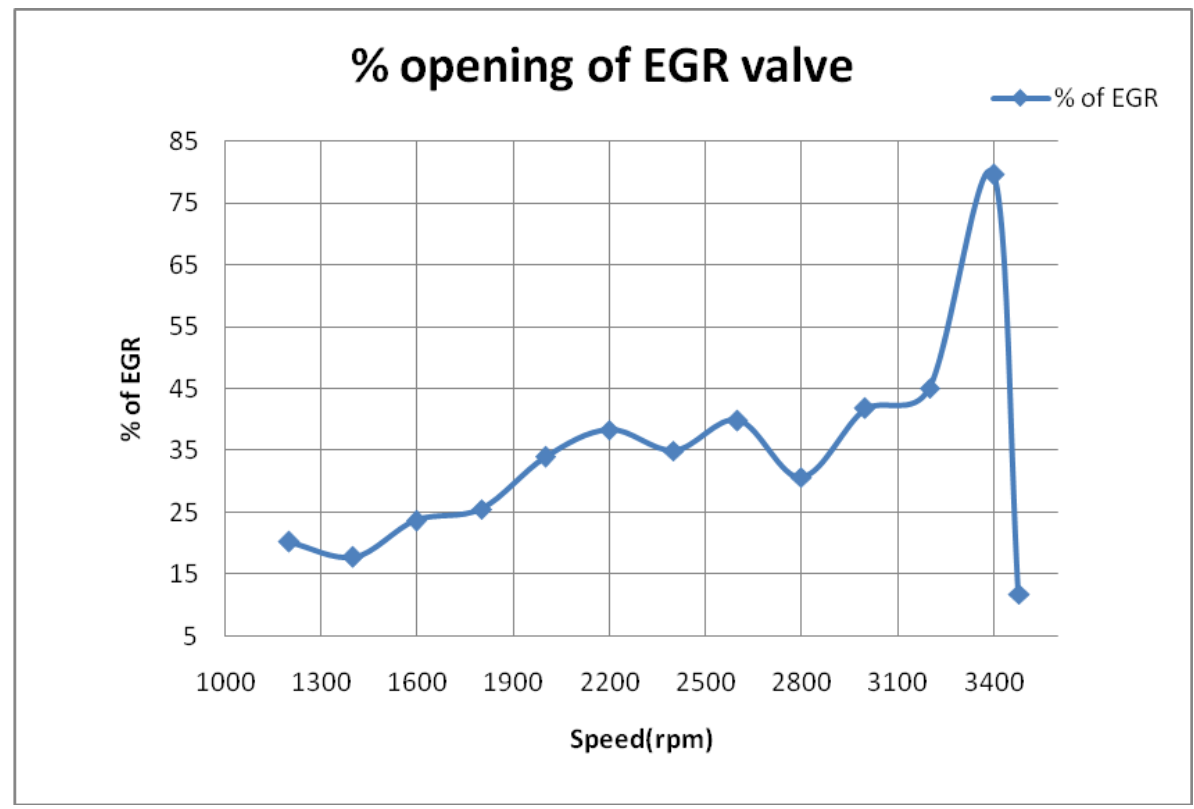

Chart -1: Graph of Speed V/s \% opening of EGR valve

Thus according with these percentages opening of EGR valve, the performance and emissions of an engine is carried out. The electronic engine posses the great reliability and flexibility during the operating of an EGR valve.
Increasing the fuel quantity with high injection pressure provides more fuel to burn in short time period with advanced ignition develops more in cylinder pressure producing better torque improvement by $16.27 \%$ than the previous engine.

\subsection{Torque}

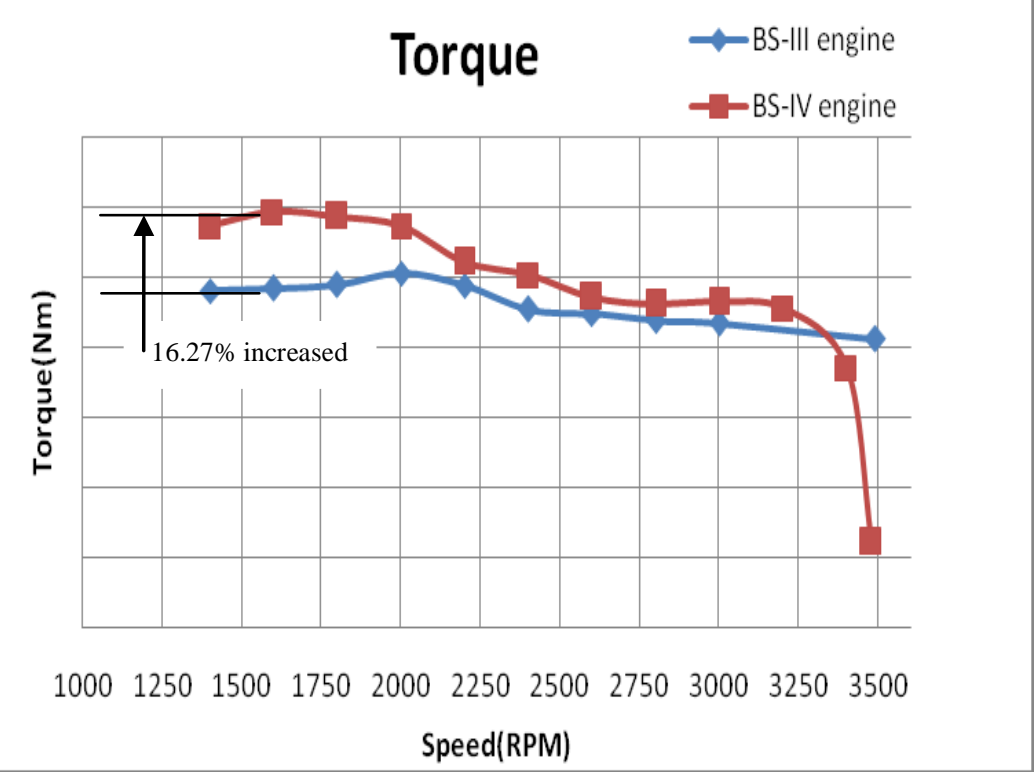

Chart -2: Graph of Torque (Nm) V/s Engine speed (rpm) 


\subsection{Power}

After the optimization it is concluded that by increasing the injection pressure for lower and higher RPM's better atomization of fuel droplets with proper mixing inside the cylinder during combustion give rises and power is improved by $8.775 \%$.

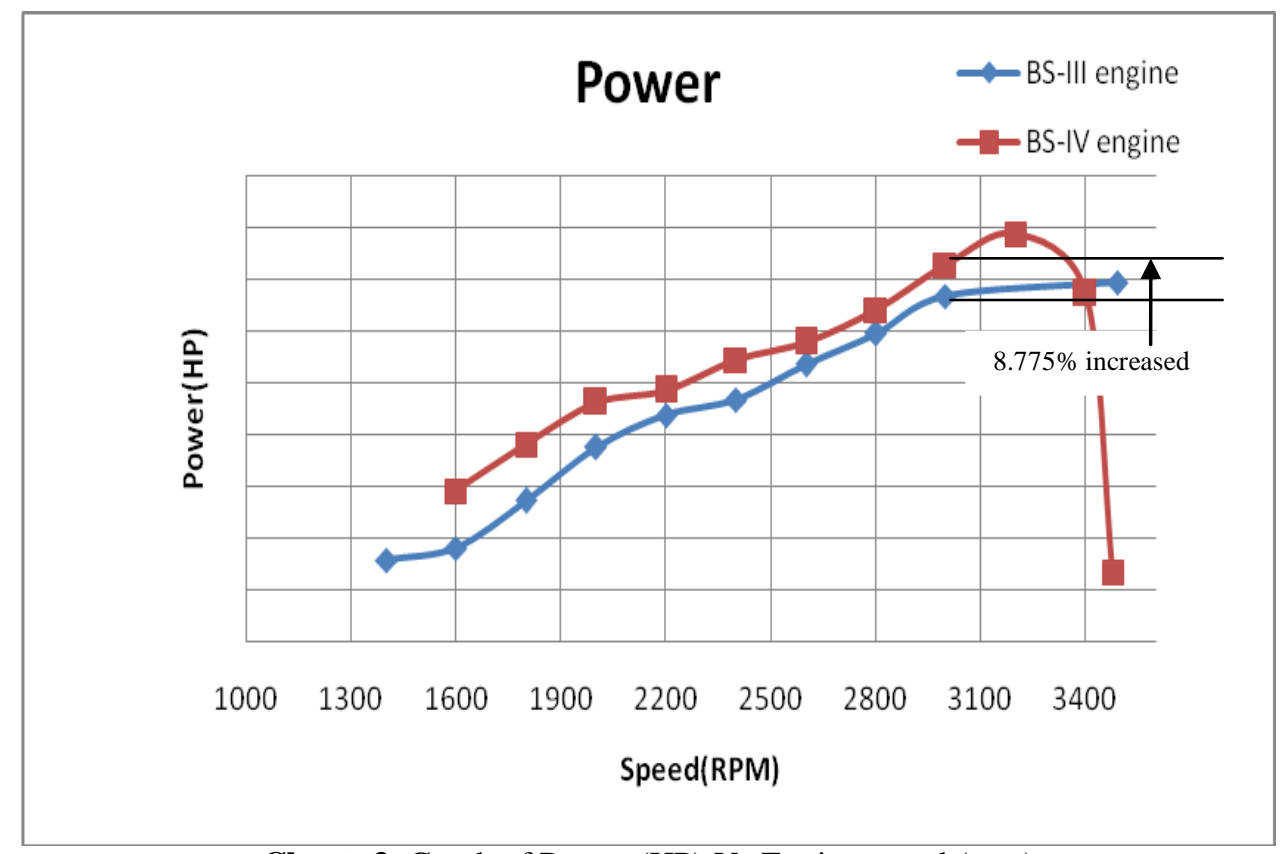

Chart -3: Graph of Power (HP) Vs Engine speed (rpm)

\subsection{Break Mean Effective Pressure}

Since the BMEP increased by $9.10 \%$ it is due the more fuel consumption enhanced engine performance by better utilization of fuel energy with less production of unburnt $\mathrm{HC}$ and incomplete combustion products like $\mathrm{CO}$ and $\mathrm{CO} 2$ by means of increased Rail Pressure and reducing the main DIT.

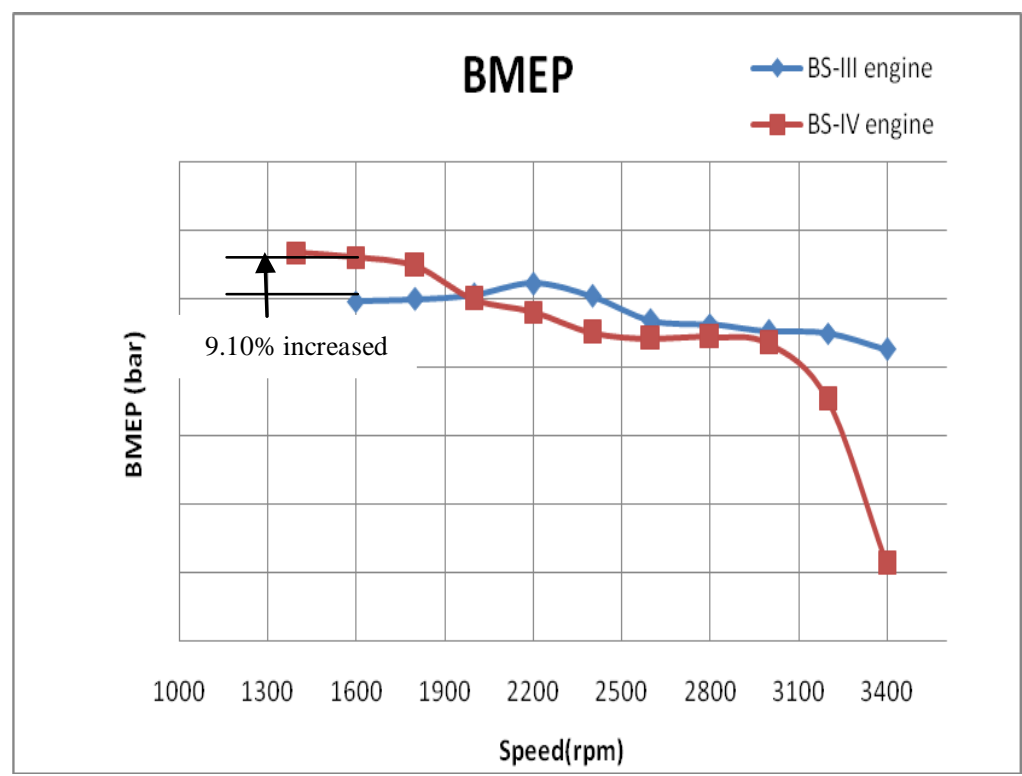

Chart -4: Graph of BMEP (bar) Vs Engine speed (rpm)

\subsection{Total Hydro-Carbon}

With the reduction of main DIT with early pilot injection tends to increase THC emission since the burning of pilot will stop very early before the main injection event would produce more THC in some operating points due to more fuel injection with less ignition timing. Optimized result in THC emission from BS IV engine with EGR ON. 


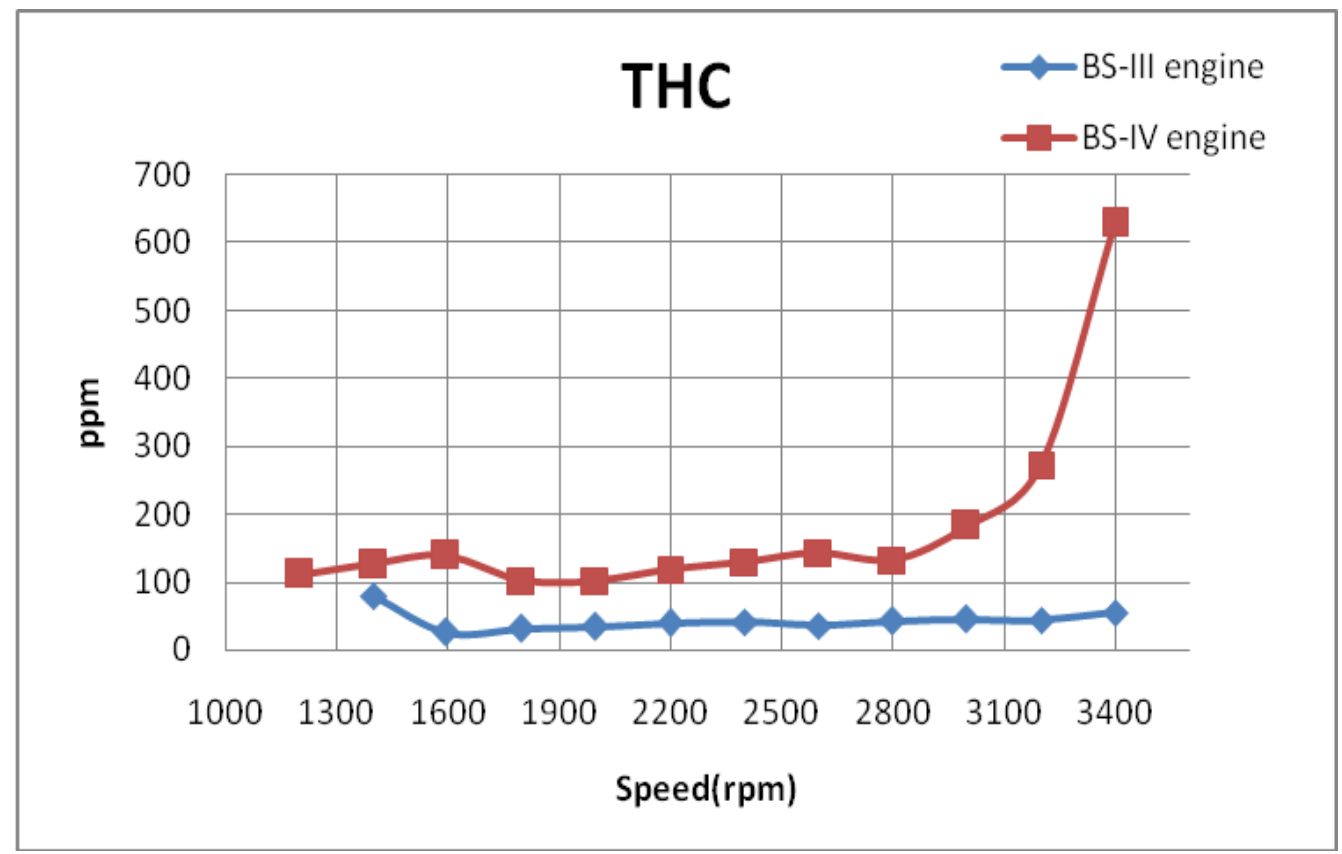

Chart -5: Graph of THC (ppm) V/s Engine speed (rpm)

\subsection{Carbon Monoxide}

Since because of the high quantity of EGR, the incomplete burning of fuel takes place as maximum quantity of fresh charge is absorbed by the EGR at the top idle speed and at high torque region.

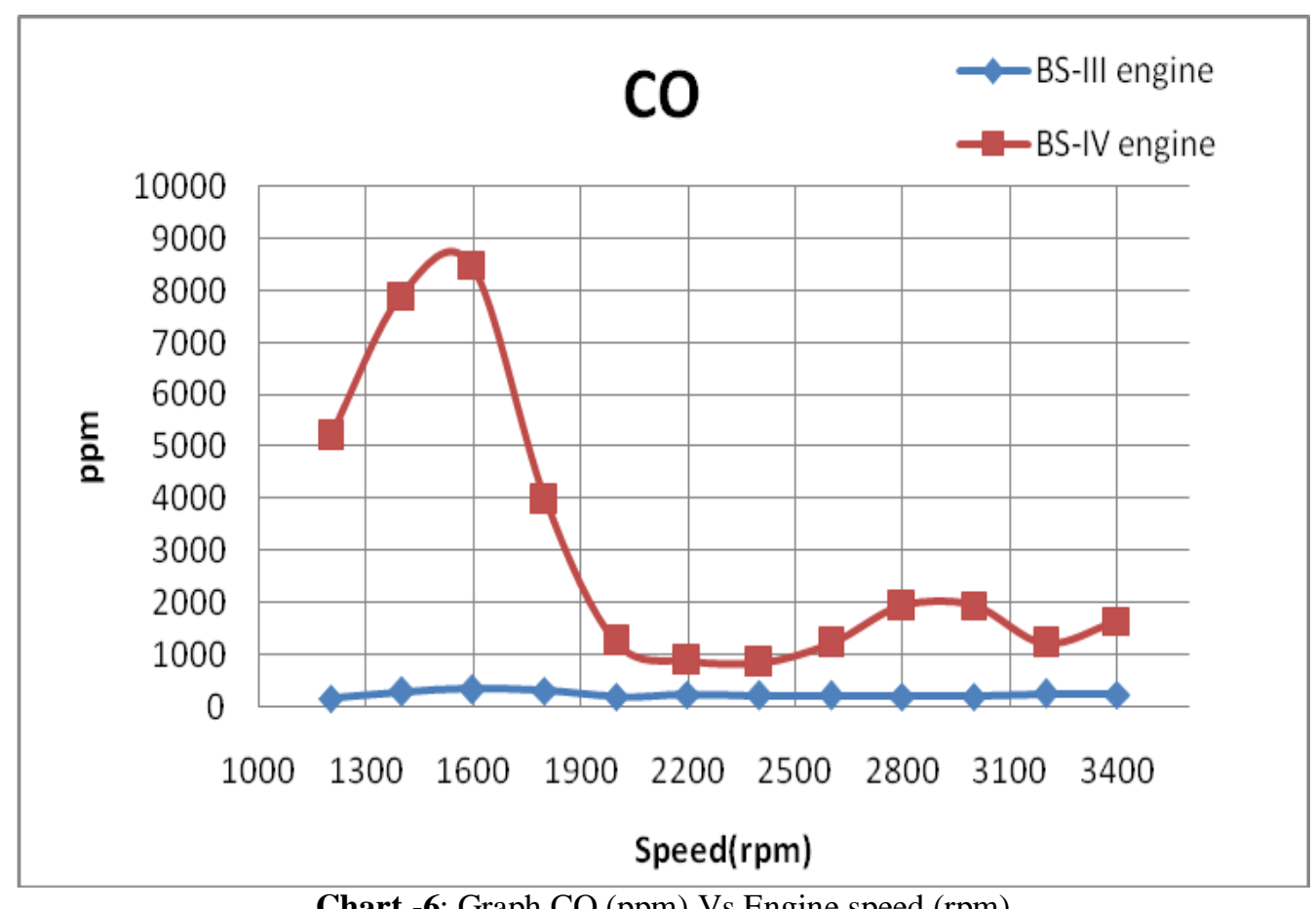

Chart -6: Graph CO (ppm) Vs Engine speed (rpm)

\subsection{Smoke}

Due to the EGR ON, the combustion of fuel is improper due to addition of exhaust gases in the combustion chamber, the mixing of fuel is improper and the maximum exhaust gases will absorbed the fresh charge which are coming through the intake manifold. Thus combustion will be incomplete and produces the smoke. 


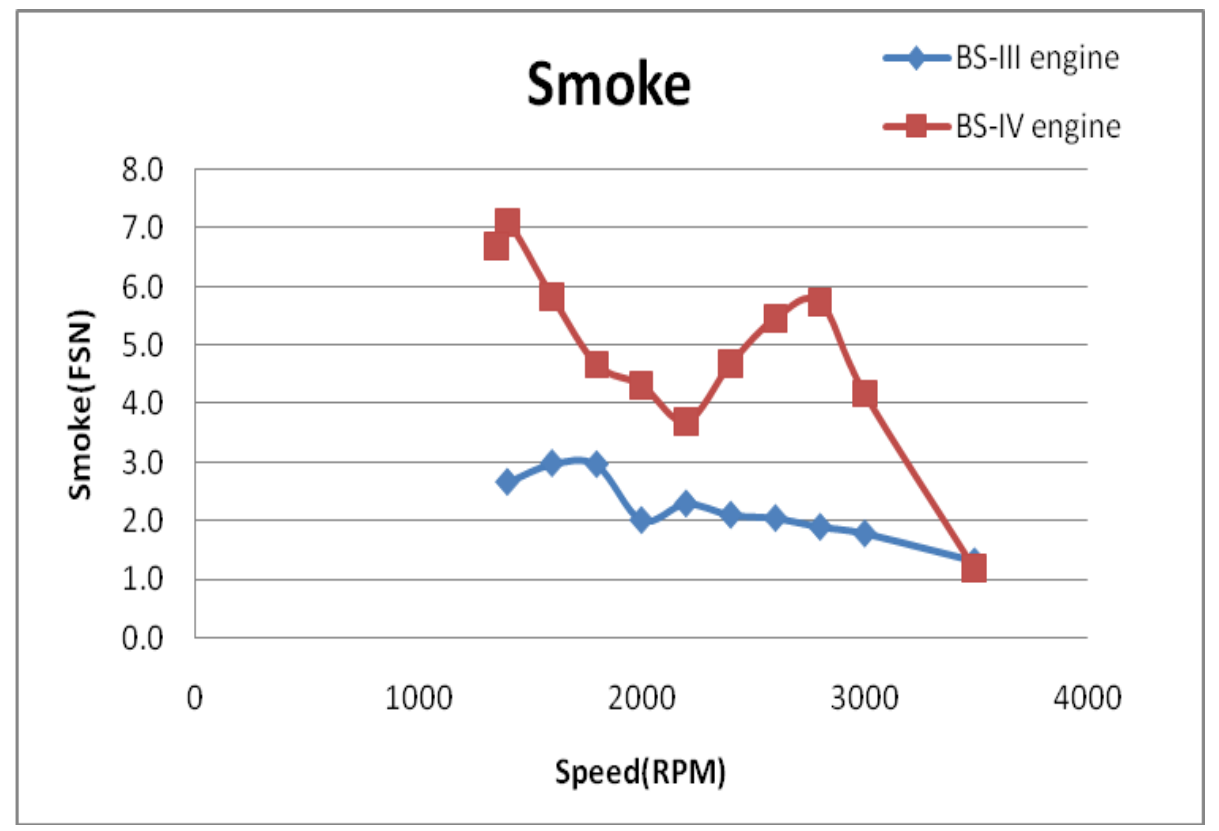

Chart -7: Graph of Smoke (ppm) V/s Speed (rpm)

\subsection{Nitrogen Oxides}

In every RPM and load condition stages we mainly considered to reduce NOx by changing EGR \% without touching performance reduction of engine or other emission parameters. There by achieving much reduction of NOx in order to satisfy BSIV emission norms.

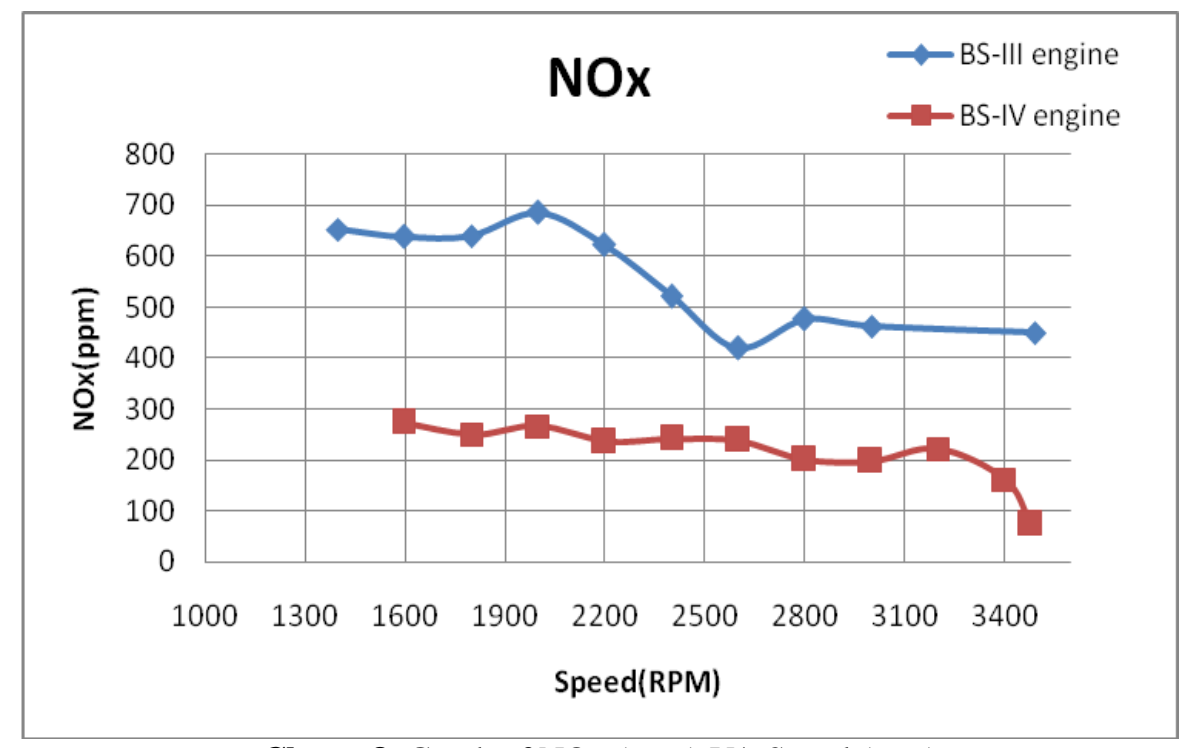

Chart -8: Graph of NOx (ppm) V/s Speed (rpm)

\subsection{Vehicle Emissions}

Since from the above graphs we conclude that the changes we are made are only for the reduction of NOx emissions, due to penalty of that we get all the emissions above the limits of BS-IV norms. Thus after getting the better performance and NOx emissions, this engine will be mounted on the vehicle and runs in the chassis dynamometer on the MIDC cycle. Since on vehicle, the implementation of DOC (30gm) and the POC (10gm) loading will be provided to the after exhaust pipe. Thus after performing a emission test in the chassis dynamometer on the MIDC cycle, the emissions will be taken in the gas analyser and final results will be displayed on the computer with the emission values with notification whether vehicle is passed in BS-IV limits or not. On the chassis dynamometer the drivability, power at wheel also can be performed. But in our case the satisfaction of emission norms are important, thus we have performed only emission test for the verification of BS-IV norms. The results of vehicle emissions are as follows 
Table -4: Vehicles exhaust emissions after testing in chassis dynamometer

\begin{tabular}{|c|c|c|c|c|c|}
\hline $\begin{array}{ll}\text { BS IV } & \text { IV }\end{array}$ & \multicolumn{2}{|c|}{ Emission } & \multicolumn{2}{|c|}{$\begin{array}{l}\text { Mass } \\
(\mathrm{g} / \mathrm{Km})\end{array}$} & $\begin{array}{l}\text { Margin } \\
(\%)\end{array}$ \\
\hline \multirow[t]{2}{*}{0.45} & \multicolumn{2}{|l|}{$\mathrm{CO}$} & \multicolumn{2}{|l|}{0.06} & 86.57 \\
\hline & \multicolumn{2}{|c|}{$\mathrm{HC}(\mathrm{C} 1)$} & \multicolumn{2}{|l|}{0.01} & \\
\hline 0.25 & \multicolumn{2}{|l|}{$\mathrm{NO}_{\mathrm{x}}$} & \multicolumn{2}{|l|}{0.217} & 13.12 \\
\hline \multirow[t]{2}{*}{0.3} & \multicolumn{2}{|c|}{$\mathrm{HC}+\mathrm{NO}_{\mathrm{x}}$} & \multicolumn{2}{|l|}{0.228} & 24.16 \\
\hline & \multicolumn{2}{|c|}{$\mathrm{CO} 2$} & \multicolumn{2}{|l|}{97.61} & \\
\hline 0.021 & \multicolumn{2}{|l|}{ PM } & \multicolumn{2}{|l|}{0.014} & 35.19 \\
\hline \multicolumn{6}{|l|}{ Result :- } \\
\hline \multicolumn{6}{|c|}{ Passed in all for BS IV Limits } \\
\hline & & \multicolumn{2}{|c|}{ Test Validity } & \multicolumn{2}{|c|}{ Valid } \\
\hline & & \multicolumn{2}{|c|}{ Results } & \multicolumn{2}{|c|}{$\mathrm{OK}$} \\
\hline & & \multicolumn{2}{|c|}{ Test Time } & \multicolumn{2}{|c|}{$15.35 \mathrm{~min}}$. \\
\hline
\end{tabular}

\section{CONCLUSIONS AND FUTURE SCOPE}

IMRL engine improved the performance and satisfied BS IV emission norms by means of optimization technique with the help of fully electronically controlled engine management system. The improvement of performance parameters was done with the help of INCA software, which is used for engine optimization procedure by means of data acquisition from engine and calibration of injection parameters. With the help of INCA calibration and data acquisition software engine optimized for FTP/PTP points with EGR and without EGR. The prime focus of optimization is to achieve BS IV emission norms with better margin in emission. While optimization the engine injection parameters Rail pressure, main DIT, main fuel, Pilot DIT, Pilot Fuel, EGR \% varied. These parameters are playing key role in performance enhancement and emission.

- Rail pressure or injection pressure plays a major role in performance improvement by means of improvement in Torque, Power, and BMEP by better atomization of fuel droplets so that better mixing, spray penetration are possible giving more homogenously combustible mixture with less smoke and other un-burnt HC.

- Main DIT also enhances the performance of the engine by injection retard hence the amount of fuel is less creates benefits in NOx reduction.

- Pilot fuel plays a major role in combustion noise, it would reduce combustion noise by partial burning there by pre conditioning the combustion chamber to develop smoother in cylinder pressure rise and less premixed combustion phases there by reducing ignition delay of main injection.

- $\quad$ EGR \% increase will reduce $\mathrm{NO}_{\mathrm{x}}$ by reducing the combustion temperature with the penalty of more smoke due to the presence of high specific heat species in the cylinder reduces $\mathrm{O}_{2}$ concentration.

- The same data set we used for the optimization in engine ECU can be used for optimizing the vehicle upon testing in chassis dynamometer. Hence no need to optimize again and it gives one more benefit of electronic control engine.
- $\quad$ From the result obtained from the graphs we could see that emission from the engine is more in the case of THC, CO and smoke. This can be better preventing with the help of POC and DOC when it would be used in the vehicle exhaust system while the engine is fitted in the vehicle.

- Finally it concludes that the IMRL system and electronic control engine is the need of future trends and useful to satisfy the BS-IV norms.

- Because of high accuracy, quick responding and closed loop system, this electronic control system will be implemented to satisfy the future emission norms.

\section{ACKNOWLEDGEMENTS}

A special thanks to Greaves Cotton Ltd. Aurangabad, for providing me the testing facility. Thanks to Mr. Prashant Dharmapurikar who gave their guidance.

\section{REFERENCES}

[1]. Pundlik R. GHODKE and Jiwak G. SURYAWANSHI "Optimisation of the 2.2 liter high speed diesel engine for proposed Bharat Stage 5 emission norms in India" THERMAL SCIENCE: Year 2014, Vol. 18, No. 1, pp. 169178.

[2]. S. Radhakrishnan and Dr. S. Jayaraj, "Upgradation of Naturally Aspirated Two Cylinder Diesel Engine to Meet CPCB-II Emission from CPCB-I Emission For Genset Application" IOSR Journal of Mechanical and Civil Engineering (IOSR-JMCE) e-ISSN: 2278-1684,p-ISSN: 2320-334X, Volume 11, Issue 2 Ver. V (Mar- Apr. 2014), PP 58-64 www.iosrjournals.org

[3]. Sandip Raut and S. D. Yadav "Emission optimization of single cylinder diesel engine by using ETAS-INCA software" Automobile Engineering Department, Rajarambapu Institute of Technology Islampur, India.

[4]. P. R. Ghodke and J. G. Suryawanshi "Investigation of multi-cylinder diesel engine to meet future indian emission norms" IJST, Transactions of Mechanical Engineering, Vol. 38, No. M1+, pp 239-252

Printed in The Islamic Republic of Iran, 2014

(C) Shiraz University.

[5]. Rahul Katariya and Ashok. J. Keche "Research on Steps Taken To Meet BSIV Emission Norms with Single Cylinder Air Cooled Diesel Biographies Engine \& Conventional Injection System" International Journal of Advances in Engineering \& Technology, Jan. 2014. CIJAET.

[6]. Keshav S. Varde and Takashi Watanabe "Characteristics of High Pressure Spray and Exhaust Emissions in a Single Cylinder DI Diesel Engine" Seoul 2000 FISITA World Automotive Congress F2000H235 June 12-15, 2000, Seoul, Korea. 


\section{BIOGRAPHIES}

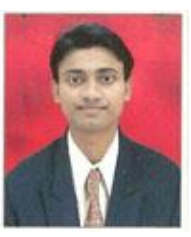

Mr. Mayur Shankarappa Sawade born in Maharashtra, India, pursuing M.E. in Automotive Engineering from Sinhgad Academy of Engineering, pune. Interest in further studies in performance and emission up-gradation of I. C. Engines.

Dr. Sandeep S. Kore is working as Associate Professor in Sinhgad Academy of Engineering, pune. His $\mathrm{PhD}$ in heat transfer and CFD. His area of interest is heat transfer enhancement in I. C. Engines. 